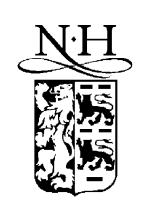

ELSEVIER

\title{
Superconducting and electro-optical thin films prepared by pulsed laser deposition technique
}

\author{
J. Schubert ${ }^{\mathrm{a}, *}$, M. Siegert ${ }^{\mathrm{a}}$, M. Fardmanesh ${ }^{\mathrm{c}}$, W. Zander ${ }^{\mathrm{a}}$, \\ M. Prömpers ${ }^{\mathrm{a}}$, Ch. Buchal ${ }^{\mathrm{a}}$, Judit Lisoni ${ }^{\mathrm{a}}$, C.H. Lei ${ }^{\mathrm{b}}$ \\ anstitut für Schicht- und Ionentechnik, Forschungszentrum Jülich GmbH, 52425 Jülich, Germany \\ ${ }^{\mathrm{b}}$ Institut für Festkörperforschung, Forschungszentrum Jülich GmbH, 52425 Jülich, Germany \\ ${ }^{\mathrm{c}}$ On leave from Electrical and Electronics Engineering Department, Bilkent University, Ankara, Turkey
}

\begin{abstract}
The pulsed laser deposition (PLD) technique is an excellent method to prepare single crystalline complex oxide thin films. We have successfully grown films for the use in HTS SQUID-devices as well as for thin film optical waveguides. The Josephson junction used in the HTS SQUIDs is formed by a step edge type grain boundary junction. The step preparation is a very critical process in the SQUID preparation to achieve reproducible low $1 / f$ noise devices. We have established a new ion beam etching process to achieve clean and steep edges in $\mathrm{LaAlO}_{3}\left(\begin{array}{lll}1 & 0 & 0\end{array}\right)$ substrates. The $1 / f$ noise of SQUIDs prepared with the new method is drastically reduced. In the process of developing thin film electro-optical waveguide modulators we investigated the influence of different substrates on the optical and structural properties of epitaxial $\mathrm{BaTiO}_{3}$ thin films. These films are grown on $\mathrm{MgO}\left(\begin{array}{lll}1 & 0 & 0\end{array}\right), \mathrm{MgAl}_{2} \mathrm{O}_{4}\left(\begin{array}{lll}1 & 0 & 0\end{array}\right), \mathrm{SrTiO}_{3}\left(\begin{array}{lll}1 & 0 & 0\end{array}\right)$ and $\mathrm{MgO}$ buffered $\mathrm{Al}_{2} \mathrm{O}_{3}\left(\begin{array}{lll}1 & \overline{1} & 0\end{array}\right)$ substrates. The waveguide losses and the refractive indices were measured with a prism coupling setup. The optical data are correlated to the results of Rutherford backscattering spectrometry/ion channeling (RBS/C), X-ray diffraction (XRD), atomic force microscopy (AFM) and transmission electron microscopy (TEM). The dielectric constant, the ferroelectric hysteresis loop and the transition temperature (ferroelectric to paraelectric state) of the $\mathrm{BaTiO}_{3}$ thin films are measured. (C) 2000 Elsevier Science B.V. All rights reserved.
\end{abstract}

Keywords: Pulsed laser deposition; rf-SQUID; High temperature superconductor; Optical waveguide

\section{Introduction}

Pulsed laser deposition (PLD) is a successful thin film deposition method for the preparation of epitaxial oxide films on different single crystalline substrates [1]. Several deposition methods like MOCVD [2], MBE [3,4] and rf magnetron sputtering [5] have been used to deposit HTS-material as $\mathrm{YBa}_{2} \mathrm{Cu}_{3} \mathrm{O}_{7-x}$, ferro-

\footnotetext{
* Corresponding author. Tel.: +49-2461-616379; fax: +49-2461-614673.

E-mail address: j.schubert@fz-juelich.de (J. Schubert).
}

electric $\mathrm{BaTiO}_{3}$ and other perovskite thin films on many different substrates. The advantage of PLD is the stoichiometric transfer of complex target materials to the substrate, which can be maintained at a high temperature in a reactive atmosphere. Many new devices may be formed using such high quality single crystalline oxide thin films. Low noise high temperature superconductor (HTS) rf-SQUIDs prepared from $\mathrm{YBa}_{2} \mathrm{Cu}_{3} \mathrm{O}_{7-x}$, which are used in the nondestructive evaluation of defects in air plane wheels, are just one example for these devices [6]. The improvement of the fabrication yield of these SQUIDs in order to achieve 
reproducible low $1 / f$ noise performance is a big challenge. We will demonstrate a new ion beam etching method to obtain clean steep steps in $\mathrm{LaAlO}_{3}\left(\begin{array}{lll}1 & 0 & 0\end{array}\right)$ which improve the yield of low noise SQUIDs drastically. Furthermore it has been shown, that $\mathrm{BaTiO}_{3}$ thin films of high transparency and good structural properties can be grown on $\mathrm{MgO}\left(\begin{array}{lll}1 & 0 & 0\end{array}\right)$ [7]. Their high quality offers the possibility to use the films for optical waveguides and devices. The large electro-optic coefficients of $\mathrm{BaTiO}_{3}$ makes this material especially suited for an electro-optical thin film modulator [8]. In this study we have investigated the influence of different substrates on the structural and optical properties of $\mathrm{BaTiO}_{3}$ thin films.

\section{Experimental}

\subsection{HTS-SQUID preparation and characterization}

Our PLD system employs a Lambda Physics LPX $305 \mathrm{KrF}$ excimer laser $(248 \mathrm{~nm}, 20 \mathrm{~ns}$, approx. $1 \mathrm{~J} /$ pulse, up to $50 \mathrm{~Hz}$ ) [9]. The laser beam is focused by a cylindrical lens $(f=400 \mathrm{~mm})$, resulting in an energy density of more than $2.5 \mathrm{~J} / \mathrm{cm}^{2}$ at the target. The cylindrical target consists of single phase $\mathrm{YBa}_{2} \mathrm{Cu}_{3} \mathrm{O}_{7-x}$ powder which has been pressed and sintered. The SQUIDs are prepared from a $200 \mathrm{~nm}$ thick epitaxial single crystalline $\mathrm{YBa}_{2} \mathrm{Cu}_{3} \mathrm{O}_{7-x}$ film prepared by PLD on a single crystalline $\mathrm{LaAlO}_{3}$ (llll $\left.\begin{array}{ll}1 & 0\end{array}\right)$ substrate $10 \mathrm{~mm} \times 10 \mathrm{~mm} \times 1 \mathrm{~mm}$. The typical deposition temperature for the $\mathrm{YBa}_{2} \mathrm{Cu}_{3} \mathrm{O}_{7-x}$ thin film was $780^{\circ} \mathrm{C}$ in an oxygen ambient of 1 mbar pure oxygen. These films show $T_{\mathrm{c}}>89 \mathrm{~K}, j_{\mathrm{c}}(T=77 \mathrm{~K})$ $>3 \times 10^{6} \mathrm{~A} / \mathrm{cm}^{2}$ and a crystalline perfection measured by the minimum yield value $\chi_{\min }<4 \%$ in a RBS/channeling analysis. In our work we use "rfwasher-SQUIDs" described elsewhere [10]. The rf-SQUIDs have a washer size of $3.5 \mathrm{~mm}$ in diameter, SQUID holes of $150 \mu \mathrm{m} \times 150 \mu \mathrm{m}$ resulting in a SQUID-inductivity of $250 \mathrm{pH}$ and a junction line width of $1-5 \mu \mathrm{m}$.

The $\mathrm{YBa}_{2} \mathrm{Cu}_{3} \mathrm{O}_{7-x}$, thin film was patterned by wet chemical etching [11] using a resist mask defined by conventional photolithography. The step formation in the substrate of the $270 \mathrm{~nm}$ deep trench was performed by an ion beam etching procedure using a resist mask defined by photolithography. The dimensions of the trench prepared in the substrates is $8 \mu \mathrm{m} \times 100 \mu \mathrm{m}$. The standard method to prepare the trenches in the substrate is to use an incident $\operatorname{Ar}^{+}$-ion beam $(U=$ $400 \mathrm{~V}, I=80 \mathrm{~mA}$ ) parallel to the normal of the substrate surface with a rotating substrate. The typical spread in the $1 / f$ noise spectra of six SQUIDs prepared in one batch, on steps prepared with this process is seen in Fig. 1.

All of these SQUIDs show a white noise level lower than $20 \mu \Phi$. at frequencies higher than $5 \mathrm{kHz}$. A large

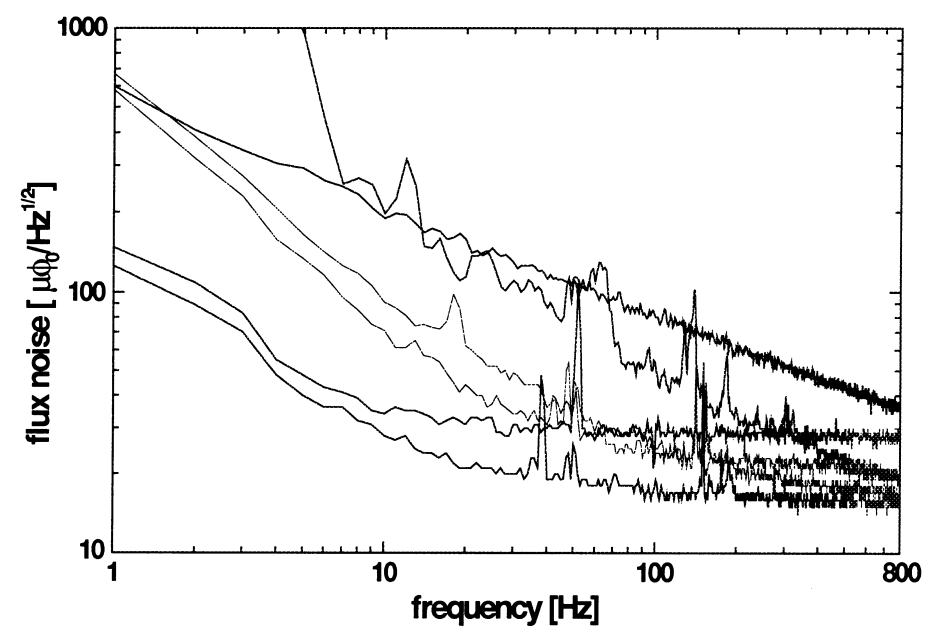

Fig. 1. Noise spectra of six rf-washer SQUIDs prepared in one fabrication cycle using the standard step edge ion-beam etching process with vertical incidence. 

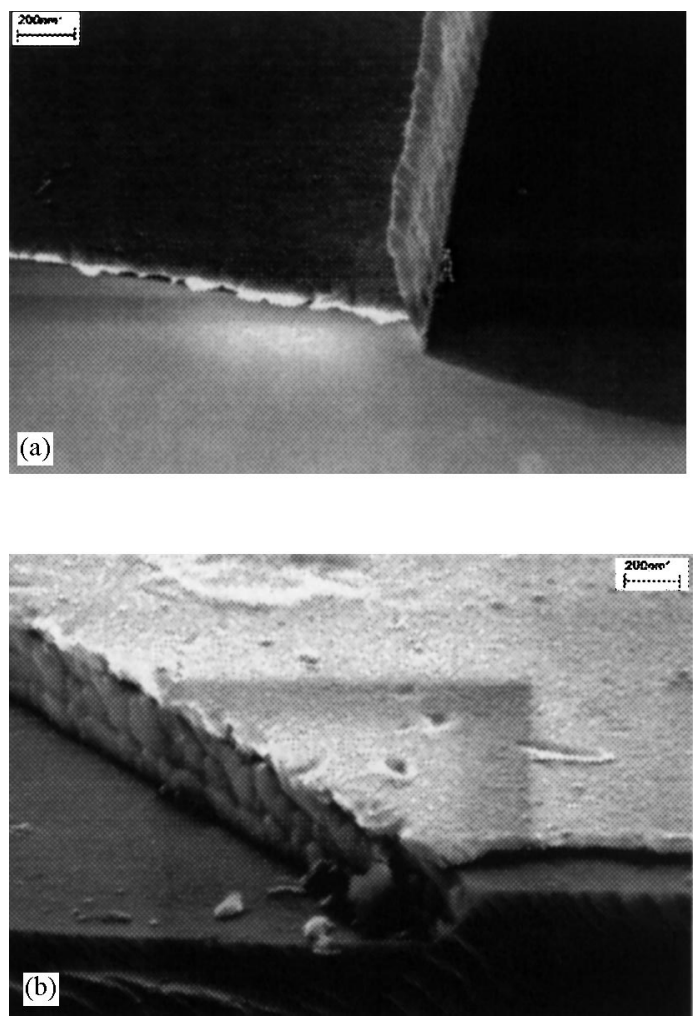

Fig. 2. (a) Redeposited material formed by amorphous substrate material covering the edge; (b) clean step in a $\mathrm{LaAlO}_{3}\left(\begin{array}{lll}1 & 0 & 0\end{array}\right)$ substrate formed by the new IBE-method.

spread in the noise behavior in the low frequency regime is clearly seen. The reason for this noise figure is found in a fence of redeposited material grown during the ion beam etching process. This fence which is seen in Fig. 2a consists of amorphous substrate material. The whole trench formed during the etching process is covered by this amorphous layer of $\mathrm{LaAlO}_{3}$.

These results indicate that the IBE-process is critical for the junction formation and the performance of the rf-SQUIDs. Hence, we have investigated the IBEprocess. The goal of our investigation was to establish an IBE-process which produces a steep clean step angle $<70^{\circ}$ as a base for step edge junctions in order to reduce the spread in the $1 / f$-noise of our rf-SQUIDs. Using a rotating substrate and an angle of incidence of $45^{\circ}$ of the ion beam with regard to the surface of the substrate we achieve a clean step with a step angle $<50^{\circ}$ (process 1) [12]. An alternative method is to align the direction of a fixed ion beam parallel to the long edge of the trench forming photoresist mask (process 2). Using the "process 2" we have found an improvement in the noise behavior of the SQUIDs. The best results were obtained using a combination of the two ion beam etching processes. At first using the "process 2", a trench is formed by a fixed ion beam which is adjusted parallel to the long edge of the trench forming edges of the photoresist. So, a $270 \mathrm{~nm}$ deep trench is formed by a fixed $\mathrm{Ar}^{+}$-beam using $500 \mathrm{eV}$ beam energy and a current of $0.5 \mathrm{~mA} / \mathrm{cm}^{2}$. The incident angle of the beam was $40^{\circ}$ with respect to the substrate surface. Then, the "process 1" was used to clean the edge surface using a rotating substrate with a beam energy of $300 \mathrm{eV}$, current density of $0.5 \mathrm{~mA} / \mathrm{cm}^{2}$ and an angle of incidence of $45^{\circ}$. The noise figures of SQUIDs prepared on these steps are seen in Fig. 3. The white noise level of these SQUIDs in comparison to the SQUIDs made with the standard process is not changed. A drastic improvement in the low frequency noise performance is visible and the noise spread is also reduced. The noise level at $10 \mathrm{~Hz}$ is approx. $30 \mu \Phi$. In conclusion, using the two IBEprocesses the $1 / f$ noise as well as the reproducibility of step edge junction rf-SQUIDs was improved dramatically.

\subsection{Electro-optical $\mathrm{BaTiO}_{3}$ thin films}

$\mathrm{BaTiO}_{3}$ thin films were prepared on different single crystalline substrates. The cylindrical target for the PLD-process consists of single phase $\mathrm{BaTiO}_{3}$ powder which has been pressed and sintered. The structural and optical parameters of these substrates are listed in Table 1. The optimized deposition conditions are very similar for all substrate materials. First the deposition chamber was evacuated to $8 \times 10^{-4} \mathrm{mbar}$ by a turbomolecular pump. Then an atmosphere of $2 \times$ $10^{-3}$ mbar of oxygen was introduced and within $5 \mathrm{~min}$ the substrates were heated to the deposition temperature by a $\mathrm{SiC}$ heater. For $\mathrm{MgO}$ and $\mathrm{SrTiO}_{3}$ substrates the heater temperature was approx. $1000^{\circ} \mathrm{C}$. For $\mathrm{MgAl}_{2} \mathrm{O}_{4}$ and $\mathrm{MgO}$ buffered $\mathrm{Al}_{2} \mathrm{O}_{3}$, a slightly higher heater temperature of approx. $1050^{\circ} \mathrm{C}$ was needed. The target-substrate distance was $4 \mathrm{~cm}$. The repetition rate of the excimer laser was kept at $10 \mathrm{~Hz}$. The growth rate was as high as $0.4 \mathrm{~nm} /$ pulse, resulting in very short deposition times of approx. $250 \mathrm{~s}$ for a $1 \mu \mathrm{m}$ thick $\mathrm{BaTiO}_{3}$ film. Directly after the deposition 


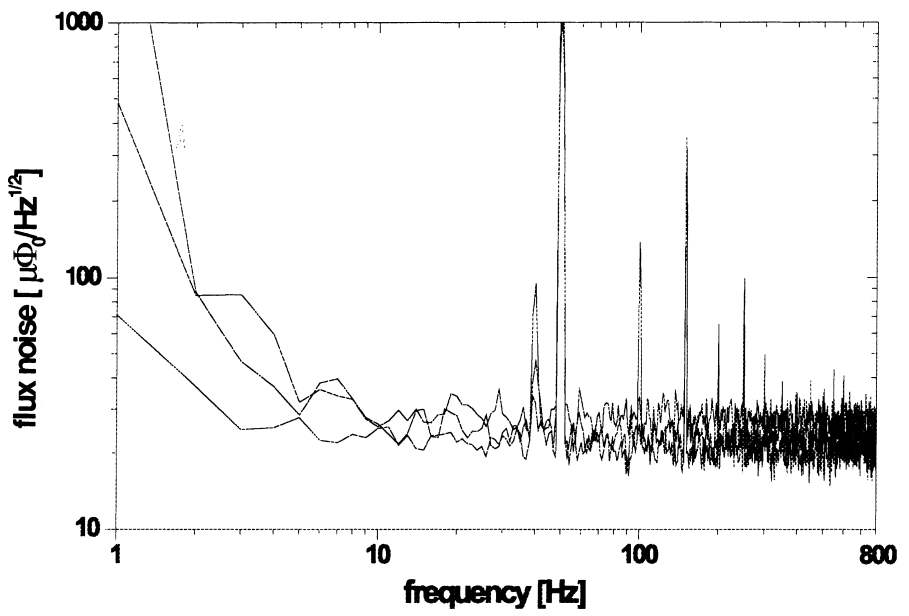

Fig. 3. Noise spectra of SQUIDs prepared with the combinational IBE method for the preparation of the step in the substrate.

the heater was switched off and the chamber was flooded with oxygen up to atmospheric pressure. After 5 min of cooling down the samples were removed from the chamber. With these parameters we obtained epitaxial $c$-axis oriented $\mathrm{BaTiO}_{3}$ films on all substrates, except on $\mathrm{MgO}$ buffered $\mathrm{Al}_{2} \mathrm{O}_{3}$, where we were able to obtain $a$-axis oriented films at $1050^{\circ} \mathrm{C}$. The low refractive index of $\mathrm{Al}_{2} \mathrm{O}_{3}$ would favor a direct deposition of $\mathrm{BaTiO}_{3}$. However, under our experimental conditions, only polycrystalline films were obtained. A $\mathrm{MgO}$ buffer layer on $\mathrm{Al}_{2} \mathrm{O}_{3}$ promotes the epitaxial growth of $\mathrm{BaTiO}_{3}$ [13].

As an example a RBS/C measurement of a $562 \mathrm{~nm}$ thick $\mathrm{BaTiO}_{3}$ film grown on $\mathrm{SrTiO}_{3}\left(\begin{array}{lll}1 & 0 & 0\end{array}\right)$ is shown in Fig. 4. The Ba:Ti ratio is 1:1 within the experimental accuracy of RBS (1 at.\%). The value of the minimum yield $\chi_{\min }$ of $0.5 \%$ measured at the Ba-signal is comparable to those observed for $\mathrm{BaTiO}_{3}$ single crystals. A summary of the RBS/C, XRD, AFM and waveguide loss measurement results of $\mathrm{BaTiO}_{3}$ films is shown in Table 2. $\mathrm{SrTiO}_{3}$ and $\mathrm{BaTiO}_{3}$ belong to the perovskite crystal family. In combination with the small misfit $(<3.3 \%)$ (Table 1), this leads to the superior structural properties of the $\mathrm{BaTiO}_{3}$ films grown on $\mathrm{SrTiO}_{3}$. Nevertheless, the high refractive index of $\mathrm{SrTiO}_{3}$ prevents the formation of waveguides. A HRTEM micrograph is shown in Fig. 5a. The interface between $\mathrm{BaTiO}_{3}$ and $\mathrm{SrTiO}_{3}$ is atomically flat. Only a low density of misfit dislocations could be observed.

For the other substrates, the HR-TEM micrographs display similar growth patterns. The interfaces are characterized by a higher number of misfit disloca-

Table 1

Structural and optical parameters of $\mathrm{BaTiO}_{3}$ and relevant substrate materials ${ }^{\mathrm{a}}$

\begin{tabular}{llllc}
\hline & $a^{\mathrm{b}}(\AA)$ & $n^{\mathrm{c}}$ & $\alpha^{\mathrm{d}}\left(10^{-6} / \mathrm{K}\right)$ & $m^{\mathrm{e}}(\%)$ \\
\hline $\mathrm{BaTiO}_{3}$ & $3.993 / 4.035$ & $2.41 / 2.36$ & $10.1-11.5$ & - \\
$\mathrm{MgO}$ & 4.213 & 1.73 & 10.5 & $-5.22 /-4.23$ \\
$\mathrm{SrTiO}_{3}$ & 3.905 & 2.39 & 10.3 & $2.25 / 3.33$ \\
$\mathrm{MgAl}_{2} \mathrm{O}_{4}$ & $8.10(2 \times 4.05)$ & 1.73 & 5.9 & $1.41 /-0.37$ \\
$\mathrm{Al}_{2} \mathrm{O}_{3}$ & $4.759 / 5.130$ & 1.76 & $5.0-5.8$ & $16.41 /-15.53$ \\
\hline
\end{tabular}

${ }^{\mathrm{a}}$ For $\mathrm{Al}_{2} \mathrm{O}_{3}$, the lattice parameters of the pseudo cubic R-cut plane are given. Since $\mathrm{BaTiO}_{3}$ is tetragonal at room temperature, first the $a-b$ and second the $c$ lattice parameters are noted.

${ }^{\mathrm{b}}$ Lattice parameter.

${ }^{\mathrm{c}}$ Refractive index at $\lambda=632.8 \mathrm{~nm}$.

${ }^{\mathrm{d}}$ Thermal expansion coefficient at $T=293 \mathrm{~K}$.

e $\left(a_{\text {film }}-a_{\text {substrate }}\right) / a_{\text {substrate }}$ : the lattice mismatch. 


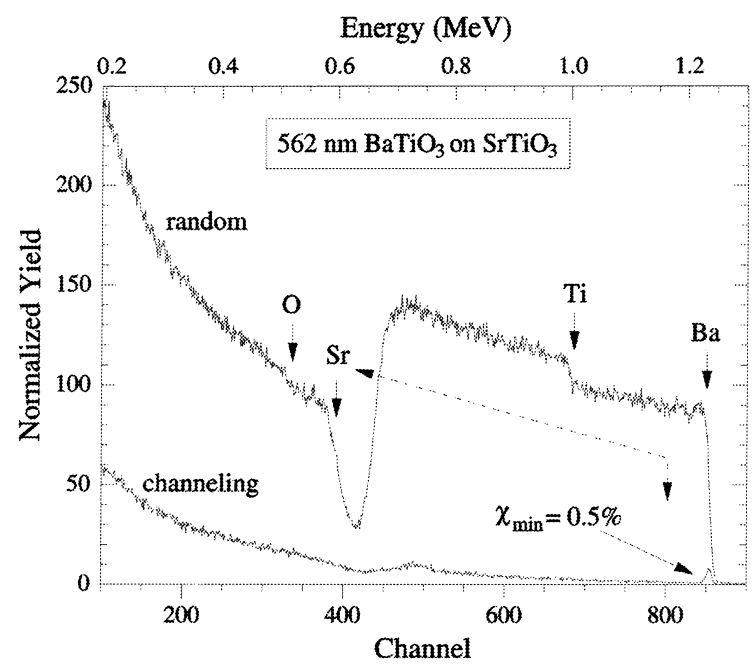

Fig. 4. RBS/channeling measurement of a $\mathrm{BaTiO}_{3}$ thin film grown on $\mathrm{SrTiO}_{3}\left(\begin{array}{lll}1 & 0 & 0\end{array}\right)$.
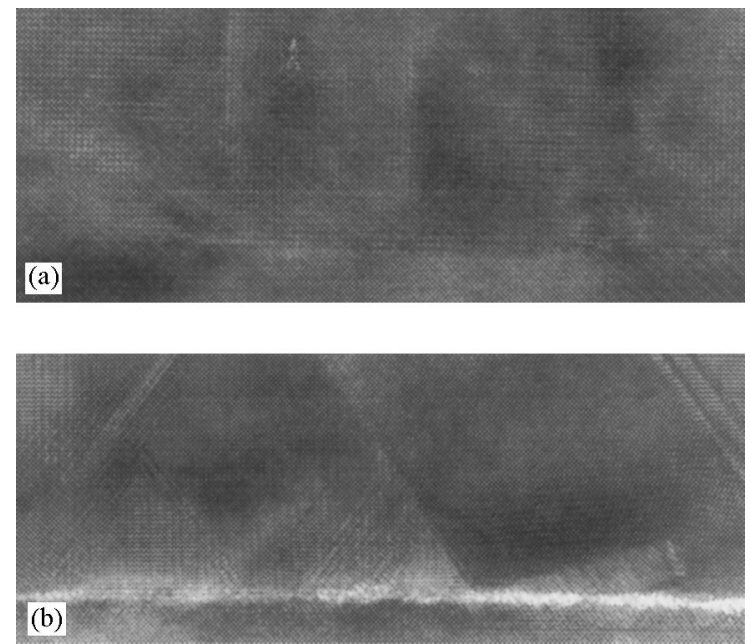

Fig. 5. High resolution TEM cross-sections of $\mathrm{BaTiO}_{3}$ films deposited on (a) $\mathrm{SrTiO}_{3}$ and (b) $\mathrm{MgAl}_{2} \mathrm{O}_{4}$ substrates.
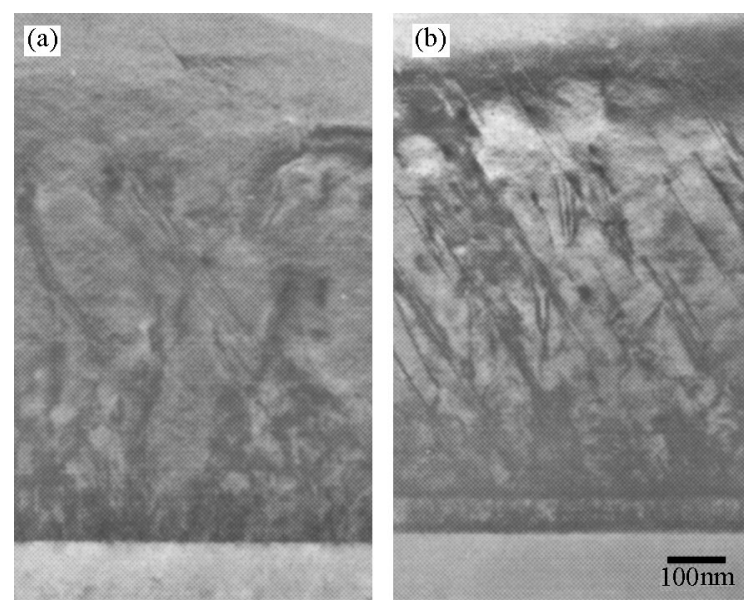

Fig. 6. TEM cross sections of $\mathrm{BaTiO}_{3}$ films deposited (a) on $\mathrm{MgO}$ and (b) on $\mathrm{MgO}$ buffered $\mathrm{Al}_{2} \mathrm{O}_{3}$ substrates. Both films show a high density of misfit dislocations near the interfaces.

tions with respect to $\mathrm{SrTiO}_{3}$. On $\mathrm{MgAl}_{2} \mathrm{O}_{4}$ also twins were visible (see Fig. 5b).

A TEM cross sectional image of a $\mathrm{BaTiO}_{3}$ film

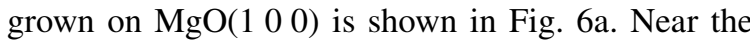
interface between $\mathrm{BaTiO}_{3}$ and $\mathrm{MgO}$, there is a high density of misfit dislocations. However, only a few of them propagate through the film up to the surface. Films on $\mathrm{MgO}$ buffered $\mathrm{Al}_{2} \mathrm{O}_{3}$ and on $\mathrm{MgAl}_{2} \mathrm{O}_{4}$ showed a somewhat higher number of defects (see Fig. 6b). TEM diffraction analysis of the samples confirmed the cubic-to-cubic orientation relationship between $\mathrm{BaTiO}_{3}$ and the different substrates, also corroborated by a X-ray $\varphi$-scan.

Because the thermal expansion coefficient of $\mathrm{Al}_{2} \mathrm{O}_{3}$ and $\mathrm{MgAl}_{2} \mathrm{O}_{4}$ is lower than that of $\mathrm{BaTiO}_{3}$, the thickness of crack free films is limited to about

Table 2

Structural and optical parameters of $\mathrm{BaTiO}_{3}$ thin films grown on different substrate materials

\begin{tabular}{llllll}
\hline Substrate & $\chi_{\text {min }}{ }^{\mathrm{a}}(\%)$ & $\Delta \omega(002)^{\mathrm{b}}\left(^{\circ}\right)$ & $\sigma^{\mathrm{c}}(\mathrm{nm})$ & $L^{\mathrm{d}}(\mathrm{dB} / \mathrm{cm})$ & Reference \\
\hline $\mathrm{SrTiO}_{3}$ & $<1$ & 0.35 & $<1$ & - & - \\
$\mathrm{MgO}$ & 1 & 0.42 & $<1$ & 3 & {$[7]$} \\
$\mathrm{MgAl}_{2} \mathrm{O}_{4}$ & 3.5 & 0.50 & 1 & 6 & - \\
$\mathrm{MgO}-\mathrm{Al}_{2} \mathrm{O}_{3}$ & 5 & 0.64 & 1 & 8 & {$[13]$} \\
\hline
\end{tabular}

${ }^{\mathrm{a}} \mathrm{RBS} / \mathrm{C}$ minimum yield for $1.4 \mathrm{MeV} \mathrm{He}{ }^{+}$ions.

${ }^{\mathrm{b}}$ Rocking curve width for the $\left(\begin{array}{lll}0 & 0 & 2\end{array}\right)$ reflex of $\mathrm{BaTiO}_{3}$.

${ }^{c}$ The rms surface roughness measured with an AFM on $3 \mu \mathrm{m} \times 3 \mu \mathrm{m}$.

${ }^{\mathrm{d}}$ Optical losses of a planar waveguide at $\lambda=632.8 \mathrm{~nm}$. 
$450 \mathrm{~nm}$. Thicker films show a micro crack pattern, which becomes visible under an optical microscope. One micrometer thick $\mathrm{BaTiO}_{3}$ films on $\mathrm{MgO}$ and $440 \mathrm{~nm}$ thick films on $\mathrm{MgO}$ buffered $\mathrm{Al}_{2} \mathrm{O}_{3}$ and on $\mathrm{MgAl}_{2} \mathrm{O}_{4}$ were used for optical waveguides.

The lowest waveguide losses of $3 \mathrm{~dB} / \mathrm{cm}$ were obtained on $\mathrm{MgO}$ substrates. This is correlated to the better structural properties in comparison to films on $\mathrm{MgO}$ buffered $\mathrm{Al}_{2} \mathrm{O}_{3}(8 \mathrm{~dB} / \mathrm{cm})$. However, one should note, that the waveguide thickness has a strong influence on the transmission losses. According to [14], the losses due to surface scattering $\alpha_{\mathrm{sc}}$ can be estimated by

$\alpha_{\mathrm{sc}}=\left(\frac{4 \pi \sigma}{\lambda}\right)^{2} \times\left(\frac{f(\varphi)}{t}\right)$

where $\sigma$ is the rms surface roughness, $\lambda$ the wavelength, $f(\varphi)$ a geometric parameter associated with the angle of reflection $\varphi$ and $t$ the waveguide thickness. The scattering losses decrease by $50 \%$ if the film thickness is increased from 500 to $1 \mu \mathrm{m}$. Changing the wavelength from 632.8 to $1.55 \mu \mathrm{m}$ decreases these losses by more than $80 \%$.

Electrical characterizations were performed using an interdigital electrode structure for capacitance measurements. In a temperature dependent measurement the transition from the ferro- to paraelectric phase was observed. The transition temperature of about $200^{\circ} \mathrm{C}$ is higher than that of single crystalline $\mathrm{BaTiO}_{3}$ bulk material $\left(120^{\circ} \mathrm{C}\right)$ which is attributed to the presence of stress in the single crystalline thin films [15]. On $\mathrm{MgO}\left(\begin{array}{lll}1 & 0 & 0\end{array}\right)$ substrates the dielectric constant of the $\mathrm{BaTiO}_{3}$ thin films has values around $\varepsilon=1000 \pm 100$. On $\mathrm{SrTiO}_{3}(100)$ these values are much higher (around $\varepsilon=3000 \pm 300$ ). The large variation in the values on different substrates is attributed to the difference in the crystalline perfection of the films. Further investigations of the dielectric constant, remanent polarization and coercitive field in this $\mathrm{BaTiO}_{3}$ thin films are in progress.

\section{Summary}

The PLD was successfully used to prepare high quality epitaxial superconducting and $\mathrm{BaTiO}_{3}$ thin films for use in optical waveguide applications.
SQUID-performance of rf-washer SQUIDs could be improved by establishing a new ion beam etching method for the preparation of the step in the substrate which prevents redeposited material at the trench steadily. Single crystalline $\mathrm{BaTiO}_{3}$ films were grown on different substrates. The best structural properties were obtained on $\mathrm{SrTiO}_{3}$. The optical losses of films on $\mathrm{MgO}$, on $\mathrm{MgAl}_{2} \mathrm{O}_{4}$ and on $\mathrm{MgO}$ buffered $\mathrm{Al}_{2} \mathrm{O}_{3}$ where 3,6 and $8 \mathrm{~dB} / \mathrm{cm}$ for $\lambda=632.8 \mathrm{~nm}$, but it is expected that these values can be reduced significantly be changing to the telecommunication wavelength of $1.55 \mu \mathrm{m}$. The relative dielectric constant of the films is depending on the substrate and the transition from the ferroelectric to the paraelectric state is observed at temperatures higher than $120^{\circ} \mathrm{C}$ (Curie temperature for bulk single crystals).

\section{Acknowledgements}

The authors gratefully acknowledge the support from the Tandetron facility and the staff of the IFF of the Forschungszentrum Jülich. This work has been supported partly by the ESPRIT Long Term Research Project No. 31838 SCOOP (Silicon Compatible Optoelectronics) and the German government founded research project No. 13N7327 "SQUID2000".

\section{References}

[1] K.L. Saenger, Process. Adv. Mat. 2 (1993) 1.

[2] D.M. Gill, B.A. Block, C.W. Conrad, B.W. Wessels, S.T. Ho, Appl. Phys. Lett. 69 (1996) 2968.

[3] F.J. Walker, R.A. McKee, Appl. Phys. Lett. 65 (1994) 1495.

[4] R.A. McKee, F.J. Walker, M.F. Chisholm, Phys. Rev. Lett. 81 (1998) 3014

[5] P. Barrios, H.K. Kim, Appl. Phys. Lett. 73 (1998) 1017.

[6] A.I. Braginski, H.-J. Krause, J. Vrba, SQUID magnetometers, in: M.H. Francombe (Ed.), Superconducting Film Devices, Handbook of Thin Film Devices, Vol. 3, Academic Press, San Diego, 2000, pp. 149-225.

[7] L. Beckers, J. Schubert, W. Zander, J. Ziesmann, A. Eckau, P. Leinenbach, Ch. Buchal, J. Appl. Phys. 83 (1998) 3305.

[8] M. Zgonik, P. Bernasconi, M. Duelli, R. Schlesser, P. Günter, M.H. Garrett, D. Rytz, Y. Zhu, X. Wu, Phys. Rev. B 50 (1994) 5941. 
[9] B. Stritzker, J. Schubert, U. Poppe, W. Zander, U. Krüger, A. Lubig, Ch. Buchal, J. Less-Common Met. 164-165 (1990) 279.

[10] Y. Zhang, M. Mück, K. Herrmann, J. Schubert, W. Zander, A.I. Braginski, C. Heiden, Appl. Phys. Lett. 60 (1992) 645.

[11] F.-M. Kamm, A. Plettl, P. Ziemann, Supercond. Sci. Technol. 12 (11) (1998) 1397-1400.
[12] K. Hermann, G. Kunkel, M. Siegel, J. Schubert, W. Zander, A.I. Braginski, C.L. Jia, B. Kabius, K. Urban, J. Appl. Phys. 78 (1995) 1131.

[13] J.G. Lisoni, M. Siegert, C.H. Lei, J. Schubert, W. Zander, Ch. Buchal, Thin films for optical wavegnide devices, Mat. Res. Soc. Symp. Proc., 2000, vol. 597, in press.

[14] B.W. Wessels, J. Crystal Growth 195 (1998) 706.

[15] S.B. Desu, J. Electrochem. Soc. 140 (1993) 2981. 